\title{
Deactivation behavior of an iron-molybdate catalyst during selective oxidation of methanol to formaldehyde
}

Raun, Kristian Viegaard; Lundegaard, Lars Fahl; Chevallier, Jacques; Beato, Pablo; Appel, Charlotte Clausen; Nielsen, Kenneth; Thorhauge, Max; Jensen, Anker Degn; Høj, Martin

\section{Published in:}

Catalysis Science \& Technology

Link to article, DOI:

10.1039/C8CY01109E

Publication date:

2018

Document Version

Peer reviewed version

Link back to DTU Orbit

Citation $(A P A)$ :

Raun, K. V., Lundegaard, L. F., Chevallier, J., Beato, P., Appel, C. C., Nielsen, K., Thorhauge, M., Jensen, A. D., \& Høj, M. (2018). Deactivation behavior of an iron-molybdate catalyst during selective oxidation of methanol to formaldehyde. Catalysis Science \& Technology, 8, 4626-4637. https://doi.org/10.1039/C8CY01109E

\section{General rights}

Copyright and moral rights for the publications made accessible in the public portal are retained by the authors and/or other copyright owners and it is a condition of accessing publications that users recognise and abide by the legal requirements associated with these rights.

- Users may download and print one copy of any publication from the public portal for the purpose of private study or research.

- You may not further distribute the material or use it for any profit-making activity or commercial gain

- You may freely distribute the URL identifying the publication in the public portal 


\title{
Deactivation Behavior of Iron-Molybdate Catalyst During Selective Oxidation of Methanol to Formaldehyde
}

\author{
Kristian Viegaard Raun $^{1}$, Lars Fahl Lundegaard ${ }^{2}$, Jacques Chevallier ${ }^{3}$, Pablo Beato ${ }^{2}$, Charlotte Clausen Appel ${ }^{2}$, Kenneth \\ Nielsen ${ }^{4}$, Max Thorhauge ${ }^{2}$, Anker Degn Jensen ${ }^{1}$, Martin $_{\mathrm{H} \not \mathrm{j}^{1 *}}$ \\ ${ }^{1}$ DTU Chemical Engineering, Technical University of Denmark, 2800 Kgs. Lyngby (Denmark) ${ }^{2}$ Haldor Topsфe A/S, 2800 \\ Kgs. Lyngby (Denmark) ${ }^{3}$ Department of Physics and Astronomy, Aarhus University, 8000 Aarhus (Denmark) \\ ${ }^{4}$ Department of Physics, Technical University of Denmark, 2800 Kgs. Lyngby (Denmark) \\ *mh@kt.dtu.dk
}

\begin{abstract}
An iron molybdate/molybdenum oxide catalyst $(\mathrm{Mo} / \mathrm{Fe}=2)$ was synthesized by a hydrothermal method and the catalyst's performance and compositional changes were followed during selective oxidation of methanol to formaldehyde for up to $600 \mathrm{~h}$. The activity was continuously measured for a series of experiments performed in a laboratory fixed-bed reactor with $10,100,250$ and $600 \mathrm{~h}$ on stream under reaction conditions $(5 \% \mathrm{MeOH}$, $10 \% \mathrm{O} 2$ in $\mathrm{N} 2$, Temp. $\left.=384-416^{\circ} \mathrm{C}, \mathrm{W} / \mathrm{F}=1.2 \mathrm{~g}_{\mathrm{cat}} \mathrm{h} \mathrm{mol}{ }^{-1} \mathrm{MeOH}\right)$. The structural and compositional changes of the catalyst were investigated by a number of techniques including: XRD, Raman spectroscopy, XPS, SEM-EDS and STEM-EDS. Methanol forms volatile species with molybdenum at reaction conditions, leading to depletion of Mo from the catalyst. Excess $\mathrm{MoO}_{3}$ was shown to volatilize and leave the catalyst during the first $10 \mathrm{~h}$ on stream, leading to an initial loss in activity of $50 \%$. From 10 to $600 \mathrm{~h}$ on stream leaching of molybdenum from the remaining iron molybdate phase $(\mathrm{Fe} 2(\mathrm{MoO} 4) 3, \mathrm{Mo} / \mathrm{Fe}=1.5)$ leads to iron rich phases $\left(\mathrm{FeMoO}_{4}\right.$ and $\mathrm{Fe}_{2} \mathrm{O}_{3}$, $\mathrm{Me} / \mathrm{Fe}<1.5$ ) and simultaneously an increase in activity to approximately 1.5 times the initial activity. Even at high degrees of molybdenum loss $(\mathrm{Mo} / \mathrm{Fe}=0.49)$ the formaldehyde selectivity remained above $92 \%$, and the combined $\mathrm{CO} / \mathrm{CO}_{2}$ selectivity was below $4 \%$. This is likely due to a surface layer of $\mathrm{MoO}_{\mathrm{x}}$ on the catalyst at all times due to segregation and a surface in equilibrium with the gaseous molybdenum compounds. After $600 \mathrm{~h}$ on stream formation of $\beta-\mathrm{MoO}_{3}$ was observed, indicating that this molybdenum oxide phase is stable to some extent under reaction conditions.
\end{abstract}




\section{Contents}

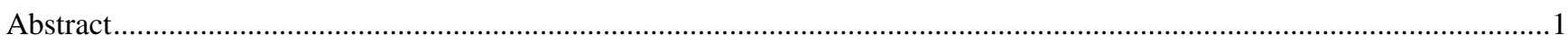

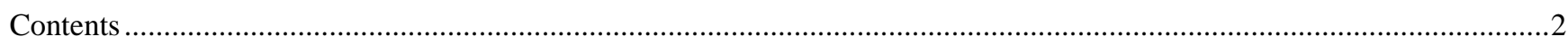

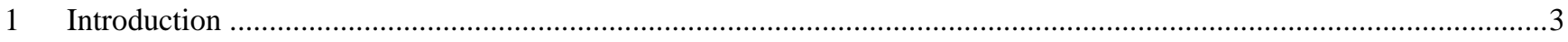

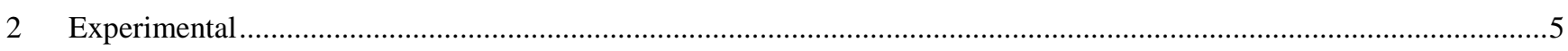

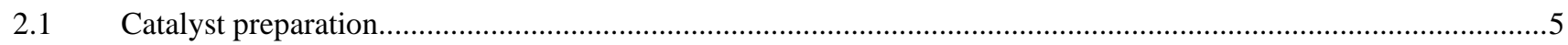

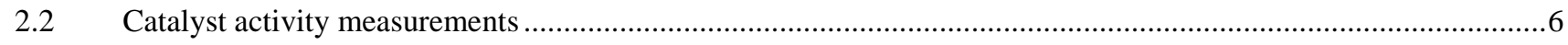

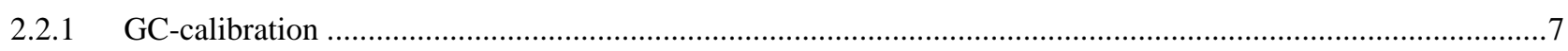

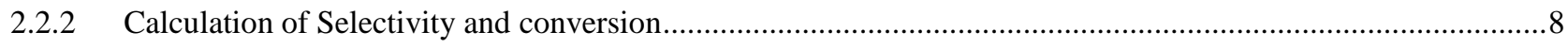

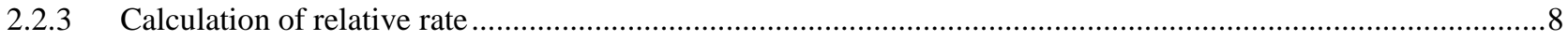

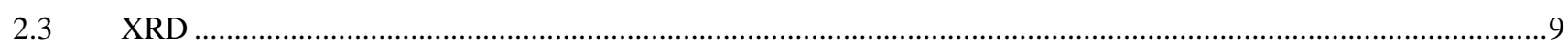

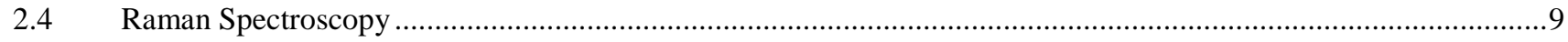

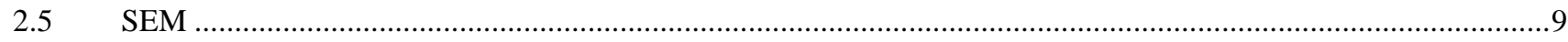

2.6 STEM

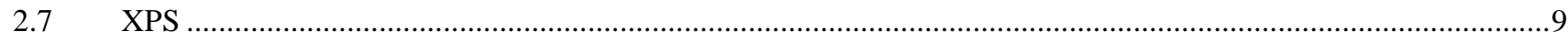

$2.8 \quad$ ICP-OES

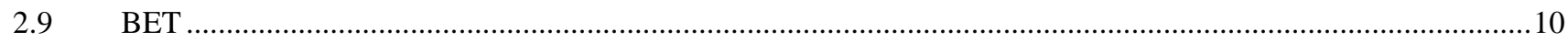

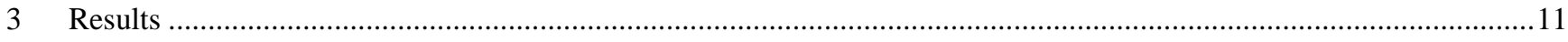

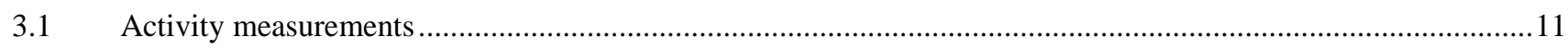

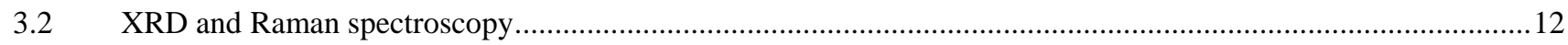

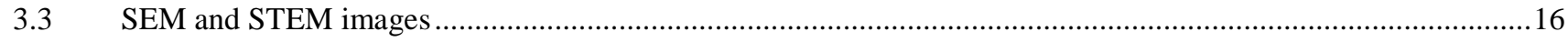

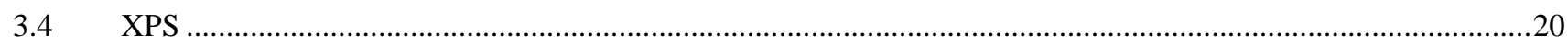

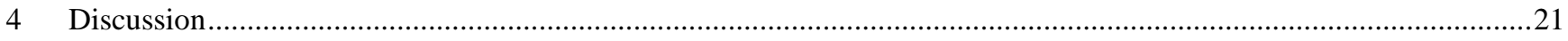

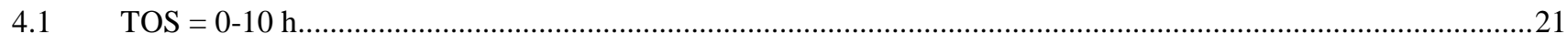

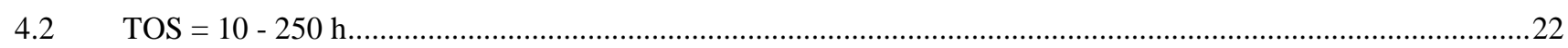

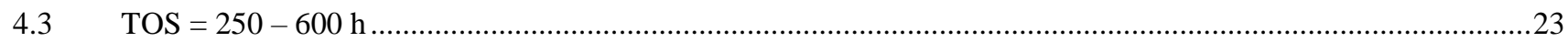

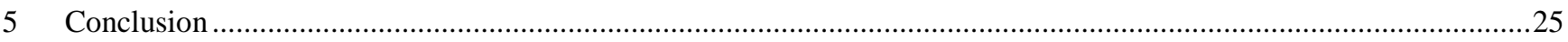

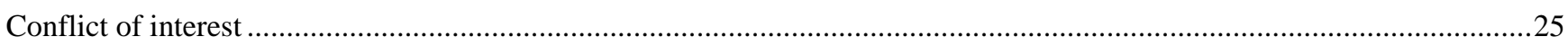

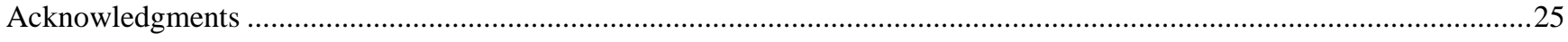

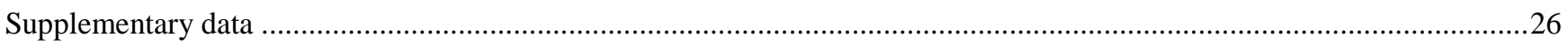

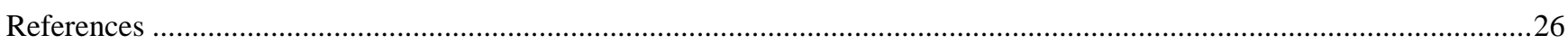




\section{Introduction}

The industrial production of formaldehyde from methanol is an important chemical process. The majority of the produced formaldehyde is processed into higher-valued synthetic resins [1], making formaldehyde an important $\mathrm{C}_{1}$ building block. Formaldehyde polymerize at room temperature and is commercially available as an aqueous solution known as formalin (37 wt.\%). The formalin production was approximately 52 million tons in 2017 [2]. Formaldehyde may be synthesized industrially by selective oxidation of methanol over an ironmolybdate/molybdenum oxide (FeMo) catalyst according to: $\mathrm{CH}_{3} \mathrm{OH}+1 / 2 \mathrm{O}_{2} \rightarrow \mathrm{CH}_{2} \mathrm{O}+\mathrm{H}_{2} \mathrm{O}(\Delta \mathrm{H}=-156$ $\mathrm{kJ} / \mathrm{mol}$ ) [3]. The reaction is normally carried out in a multitubular reactor (tube length $=1$ to $1.5 \mathrm{~m}$ ) with excess of oxygen $\left(\mathrm{MeOH}=10 \%, \mathrm{O}_{2}=10 \%\right.$ in $\left.\mathrm{N}_{2}\right)$ at near atmospheric pressure and $270-400{ }^{\circ} \mathrm{C}$ (yield $=88-92 \%$ with complete methanol conversion in a single pass), known as the Formox process [1]. Since the early 1960s the inlet concentration of methanol has increased from 6.5 to $10 \%$ methanol, which significantly increases productivity [4]. The fresh catalyst consists of two phases $\mathrm{Fe}_{2}\left(\mathrm{MoO}_{4}\right)_{3}$ and $\mathrm{MoO}_{3}$. The role of the two phases has been discussed in the literature and mainly two explanations have been suggested. One explanation is that the $\mathrm{MoO}_{3}$ phase forms a thin surface layer on the $\mathrm{Fe}_{2}\left(\mathrm{MoO}_{4}\right)_{3}$ bulk phase. This molybdenum rich surface is selective towards formaldehyde while the iron in the sublayer increases the activity of the catalyst [5], [6]. Pure $\mathrm{MoO}_{3}$ has low activity. Another explanation is that $\mathrm{Fe}_{2}\left(\mathrm{MoO}_{4}\right)_{3}$ is the active phase and that $\mathrm{MoO}_{3}$ must be present to replenish molybdenum lost from the iron molybdate surface and avoid formation of less selective iron rich phases [7]-[10].

Molybdenum forms volatile species with methanol and potentially water under reaction conditions, which can leave behind molybdenum poor zones in the catalyst bed [11], [12]. Besides the ferric molybdate phase $\left(\mathrm{Fe}_{2}\left(\mathrm{MoO}_{4}\right)_{3}\right)$ present in the fresh catalyst, the reduced ferrous phase $\left(\mathrm{FeMoO}_{4}\right)$ can be present in the spent catalyst. At substantial molybdenum loss $\mathrm{Fe}_{2} \mathrm{O}_{3}$ can be formed. Due to segregation of molybdenum in ferric molybdate, this phase tends to have an over stoichiometric Mo/Fe ratio on the surface [13].

The Selective oxidation of methanol to formaldehyde follows the Mars-van-Krevelen mechanism with initial reduction of the iron atoms (1)[14]:

$$
\mathrm{CH}_{3} \mathrm{OH}+\mathrm{Fe}_{2}\left(\mathrm{MoO}_{4}\right)_{3} \rightarrow \mathrm{CH}_{2} \mathrm{O}+\mathrm{H}_{2} \mathrm{O}+2 \mathrm{FeMoO}_{4}+\mathrm{MoO}_{3}
$$

In the presence of excess $\mathrm{MoO}_{3}$, the catalyst surface is re-oxidized without formation of iron rich species (2) [12]:

$$
2 \mathrm{FeMoO}_{4}+\mathrm{MoO}_{3}+\frac{1}{2} \mathrm{O}_{2} \rightarrow \mathrm{Fe}_{2}\left(\mathrm{MoO}_{4}\right)_{3}
$$

However if there is shortage of $\mathrm{MoO}_{3}$ the re-oxidation may result in the formation of hematite (3) [14]: 


$$
3 \mathrm{FeMoO}_{4}+\frac{3}{2} \mathrm{O}_{2} \rightarrow \mathrm{Fe}_{2}\left(\mathrm{MoO}_{4}\right)_{3}+\frac{1}{2} \mathrm{Fe}_{2} \mathrm{O}_{3}
$$

The $\mathrm{MoO}_{3}$ and $\mathrm{Fe}_{2}\left(\mathrm{MoO}_{4}\right)_{3}$ phases are primarily selective towards formaldehyde, however $\mathrm{FeMoO}_{4}$ and $\mathrm{Fe}_{2} \mathrm{O}_{3}$ are reported to be selective towards $\mathrm{CO}$ and $\mathrm{CO}_{2}$ respectively. Molybdenum oxide must be sufficiently available at the catalyst surface to ensure selectivity towards formaldehyde [15]. The commercial catalyst is prepared with excess $\mathrm{MoO}_{3}(\mathrm{Mo} / \mathrm{Fe}>1.5)$ to counter the loss of molybdenum [16]. Furthermore, excess $\mathrm{MoO}_{3}$ increases the mechanical strength of the catalyst pellets, preventing crumbling and the resulting reactor plugging by catalyst fines[17]. The average lifetime of the industrial catalyst is only 1-2 years depending on the operating conditions. Full scale experiments have been performed for the total lifetime of industrial catalysts followed by characterization. At full scale the formed volatile molybdenum species flow along the reactor and as the methanol is converted, the volatile molybdenum species decompose to molybdenum oxide and accumulate near the reactor hot spot [12], [18]. The precipitation of molybdenum oxide leads to significant increase in pressure drop, process shutdown and change of the catalyst. The pressure drop increase is the main reason for the short lifetime of the process, rather than decreasing selectivity.

Laboratory studies have been performed to investigate the degradation phenomena of the FeMo catalyst[9], [19]. In these studies a fixed-bed reactor is operated at high space time achieving high conversion. At high degree of conversion, it is difficult to measure changes in the catalyst activity. Furthermore, Popov et al. [11] observed a saturation of the gas by volatile molybdenum species at low space time and moderate temperature. For a fixedbed reactor operated at high space time, the gas will be saturated with the volatile molybdenum species in the first part of the catalyst bed and the subsequent part will be shielded from loss of molybdenum. The varying molybdenum loss in the reactor will lead to uneven degradation of the catalyst bed. The space time and methanol conversion must be sufficiently low to be able to measure uniform deactivation due to loss of molybdenum, As the methanol inlet concentration and process productivity has increased through the last decades, the short life time of the process remains a major challenge. Even though spent catalysts from industrial reactors have been investigated, the understanding of the structural and compositional changes over time and their effect on the catalyst performance is limited. To increase the catalyst stability and the process lifetime a detailed understanding of the catalyst deactivation behavior must first be established. This work presents a study of the continuous deactivation behavior and structural changes in the FeMo catalyst during selective oxidation of methanol to formaldehyde, determined by prolonged activity tests and comprehensive characterization of spent catalyst exposed to high temperature and low space time with intermediate conversion of methanol. 


\section{Experimental}

\subsection{Catalyst preparation}

The iron molybdate catalyst was prepared by hydrothermal synthesis similar to the procedure reported by Beale et al. [20]. Iron nitrate nonahydrate $\left(\mathrm{Fe}\left(\mathrm{NO}_{3}\right) \cdot 9 \mathrm{H}_{2} \mathrm{O}-\right.$ Sigma Aldrich $>98 \%$ purity $)$ and ammonium heptamolybdate tetrahydrate $\left(\left(\mathrm{NH}_{4}\right)_{4} \mathrm{Mo}_{7} \mathrm{O}_{24} \cdot 7 \mathrm{H}_{2} \mathrm{O}\right.$ - Sigma Aldrich $>99 \%$ purity) were dissolved separately in equal amounts of demineralized water (2 times $150 \mathrm{~mL}$ ). The ammonium heptamolybdate solution was dropwise added to the iron nitrate solution under vigorous stirring. Some precipitation occurred immediately after mixing. The mixture was loaded in a $400 \mathrm{~mL}$ Teflon-lined autoclave with a magnetic stirrer and the $\mathrm{pH}$ was measured (1.66). The autoclave was sealed, heated to $180^{\circ} \mathrm{C}$ and kept at this temperature for hydrothermal treatment of the mixture for 12 hours. The solid product was filtered, washed with demineralized water and dried at $60{ }^{\circ} \mathrm{C}$ overnight yielding a yellow/green powder (yield $=92 \%$ ). Finally the powder was calcined at $535{ }^{\circ} \mathrm{C}$ for $2 \mathrm{~h}$. The composition of the obtained material was determined to $\mathrm{Mo} / \mathrm{Fe}=2.01$ by inductively coupled plasma (ICP) analysis. 


\subsection{Catalyst activity measurements}

The synthesized catalyst powder was pressed into a pellet, crushed and sieved to a 150-250 $\mu \mathrm{m}$ sieve fraction. A

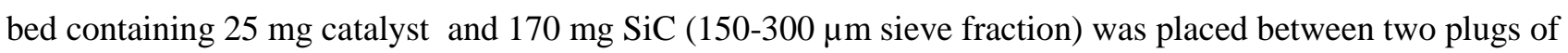
quartz wool in a U-tube reactor (ID = $4 \mathrm{~mm}$ ). The reactor was placed in an oven. The feed gas consisted of 10 vol.\% $\mathrm{O}_{2}$ and $\sim 5$ vol. $\% \mathrm{MeOH}$ in $\mathrm{N}_{2}$, which was fed at a flowrate of $\sim 157.5 \mathrm{~mL} / \mathrm{min}$ (1 bar, $\left.273.15 \mathrm{~K}\right)$. $\mathrm{N}_{2}$ and $\mathrm{O}_{2}$ were introduced by mass flow controllers (Brooks) and bubbled through a flask containing $\mathrm{MeOH}(\geq 99.9 \%$, Sigma-Aldrich). The gas was saturated with $\mathrm{MeOH}$ and the concentration was controlled by cooling the bubbleflask in a cooling bath to $5{ }^{\circ} \mathrm{C}$. To determine the conversion and selectivity the gas composition was measured at the outlet of the reactor by a gas chromatograph (GC)(Thermo Scientific, Trace GC Ultra). The MeOH and DME concentrations were measured using an FID-detector and the $\mathrm{CH}_{2} \mathrm{O}, \mathrm{H} 2 \mathrm{O}, \mathrm{CO}, \mathrm{CO}_{2}, \mathrm{O}_{2}$ and $\mathrm{N}_{2}$ concentrations were measured using a TCD-detector. The measured concentrations were corrected for expansion of the gas due to reaction using the $\mathrm{N}_{2}$ signal as internal standard [21]. Furthermore, the reactor inlet and outlet pressures were measured, and a thermocouple was placed inside the reactor touching the exit of the catalyst bed to measure the bed temperature. Before each experiment, the catalyst bed was thermally treated at $400{ }^{\circ} \mathrm{C}$ in air for two hours and the conversion was subsequently measured at increasing temperatures (oven temp. $=250,300$, 340 and $375{ }^{\circ} \mathrm{C}$ ) under reaction conditions to obtain the first order reaction rate constant as a function of temperature. Due to fast changes in the catalyst activity under reaction condition, the oven temperature was increased without $\mathrm{MeOH}$ in the feed $\left(10 \% \mathrm{O}_{2}\right.$ in $\left.\mathrm{N}_{2}\right)$. When the oven temperature stabilized at the given temperatures, $\mathrm{MeOH}$ was introduced for $5 \mathrm{~min}$ followed by an activity measurement. The measurement at 375 ${ }^{\circ} \mathrm{C}$ is the first measurement of the prolonged deactivation experiment. The changes in the catalyst activity prior to the experiment are small due to the short exposure time and moderate temperature. The four initial activity measurements were subsequently used to generate an Arrhenius plot to provide the activation energy and preexponential factor to be used for calculation of the relative rate constant as explained in Section 2.2.3. The experiments ran for 10, 100, 250 and $600 \mathrm{~h}$ respectively (oven temp. $=375^{\circ} \mathrm{C}, 1 \mathrm{GC}$-measurement $/$ hour). The industrial reaction temperature is $270-400{ }^{\circ} \mathrm{C}$ and the catalyst life time is $1-2$ years. To achieve a fast deactivation rate it was decided to run the oven at $375{ }^{\circ} \mathrm{C}$, achieving a catalyst temperature of $384-416{ }^{\circ} \mathrm{C}$ due to the exothermic reaction, which is at the upper limit of the industrial reaction temperature. The samples were cooled to room temperature in the reaction gas mixture to maintain the catalyst state. 


\subsubsection{GC-calibration}

Both GC detectors (FID and TCD) were calibrated using gas mixtures with known concentrations, except for formaldehyde due to its ability to polymerize at room temperature. The TCD detector was calibrated for formaldehyde using Lennard-Jones parameters to calculate the viscosity and thermal conductivity for formaldehyde and reference species $\left(\mathrm{N}_{2}, \mathrm{O}_{2}, \mathrm{MeOH}\right.$ and $\left.\mathrm{CH}_{4}\right)$. A linear trend between the TCD detector response factor and the thermal conductivity for the respective reference species were seen. Assuming that the response factor for formaldehyde fits the linear trend of the reference species its response factor could be estimated [22]-[24]. The response factor of formaldehyde was similar to the response factors for $\mathrm{N}_{2}, \mathrm{O}_{2}$ and $\mathrm{MeOH}$, which have similar molar masses. 


\subsubsection{Calculation of Selectivity and conversion}

The selectivities and conversions were normalized to $100 \%$ by assuming that all measured carbon species in the product stream originated from methanol in the feed according to (4) and (5):

$$
\begin{gathered}
\text { Selec. }\left(\mathrm{CH}_{2} \mathrm{O}\right)=\frac{P_{\mathrm{CH}_{2} \mathrm{O}}}{P_{\mathrm{MeOH}}+P_{\mathrm{CH}_{2} \mathrm{O}}+2 P_{\mathrm{DME}}+P_{\mathrm{CO}}+P_{\mathrm{CO}_{2}}} * 100 \% \\
\text { Conversion }=\left(1-\frac{P_{\mathrm{MeOH}}}{P_{\mathrm{MeOH}}+P_{\mathrm{CH}_{2} \mathrm{O}}+2 P_{\mathrm{DME}}+P_{\mathrm{CO}}+P_{\mathrm{CO}_{2}}}\right) * 100 \%
\end{gathered}
$$

\subsubsection{Calculation of relative rate}

The catalyst temperature was not constant through the experiments due to the exothermic reaction, which will affect the degree of conversion. To compensate for the changing catalyst temperature on the apparent activity in terms of conversion, a relative rate constant was calculated for each gas sampling time (1 sample per hour) in the activity measurements. The relative rate constant is the ratio between the measured rate constant and the calculated rate constant of the fresh catalyst at the catalyst temperature at the sampling time. The measured rate is calculated from the degree of conversion at the sample-time and the expected rate of the fresh catalyst is calculated from the catalyst temperature at the sample-time and the initially measured Arrhenius parameters. The reaction order of Methanol is reported to be first order [25], [26] and the relative rate constant is calculated according to (6)-(8) as explained above. The measured rate constant is calculated from the plug flow reactor design equation (6) and the expected rate constant of the fresh catalyst is determined from the Arrhenius parameters (7). The relative rate constant is the ratio between measured and expected rate constant of the fresh catalyst (8) at the reactor temperature at the time of sampling.

$$
\begin{gathered}
\boldsymbol{k}_{\text {Meas }}(T)=-\frac{v_{0}}{W} * \ln (1-X) \\
\boldsymbol{k}_{\text {Fresh }}(T)=A * \exp \left(\frac{-E_{a}}{R T}\right) \\
\boldsymbol{k}_{\text {Relative }}=\frac{\boldsymbol{k}_{\text {Meas }}(T)}{\boldsymbol{k}_{\text {Fresh }}(T)}
\end{gathered}
$$

Where $v_{0}$ is the volumetric flow rate, $W$ is the catalyst mass, $X$ is the degree of conversion, $A$ is the preexponential factor, $E_{a}$ is the activation energy, $R$ is the gas constant and $T$ is the absolute temperature. 


\subsection{XRD}

XRD data were collected using a PanAlytical Empyrean diffractometer equipped with focusing mirrors for $\mathrm{CuK} \alpha$ radiation $(\lambda=1.541 \AA$ ) and a capillary spinner. A Ni beta filter, a pair of 0.04 radian soller slits and a beam stop was further more used. Samples were measured in sealed capillaries. Rietveld refinement was performed using the TOPAS software [27] and reference structures for $\mathrm{Fe}\left(\mathrm{MoO}_{4}\right)_{3}$ [ICSD 80449], $\mathrm{FeMoO} 4$ [ICSD 43013], $\alpha-\mathrm{MoO}_{3}$ [ICSD 152313], $\beta-\mathrm{MoO} 3$ [ICSD 86426] and $\mathrm{Fe}_{2} \mathrm{O}_{3}$ [ICSD 15840]. Atomic positions and stoichiometry were fixed while lattice parameters, average crystallite size and scale factors were refined.

\subsection{Raman Spectroscopy}

Raman spectra were recorded with a Horiba LabRAM microscope, using $633 \mathrm{~nm}$ excitation. The samples were sealed in glass capillaries in order to avoid re-oxidation in air during measurements. A 50x long distance objective (Olympus) was used to focus the laser beam, with a measured power of $1 \mathrm{~mW}$ on the sample. Tests with higher and lower laser power were done to check for sample laser damage, which was only observed in the case of the sample run for $600 \mathrm{~h}$ time on stream. Reference spectra for all relevant phases are shown in Figure S1†.

\section{$2.5 \quad$ SEM}

The particles were dispersed on double sided carbon tape on an aluminium stub and the samples were coated with an electron conductive layer of carbon prior to investigation. Scanning Electron Microscopy (SEM) images were acquired in an Environmental SEM, XL30 FEG, at $15 \mathrm{kV}$ and the backscattered electron signal was used. EDX analyses in SEM were acquired without standards at $15 \mathrm{kV}$ with an EDAX liquid Nitrogen cooled $\mathrm{Si}(\mathrm{Li})$ detector.

\subsection{STEM}

X-rays maps were acquired using a FEI Talos (S)TEM running at $200 \mathrm{kV}$ in Scanning Transmission Electron Microscopy (STEM) mode and implanted with the ChemiSTEM technology consisting of 4 SDD X-rays detectors distributed symmetrically around the sample.

\subsection{XPS}

XPS was performed with a Theta Probe system from Thermo Fisher. The system utilizes monochromatized Al $\mathrm{K}_{\alpha} \mathrm{X}$-rays with an energy of $1486.7 \mathrm{eV}$ as the source and the spot size was set to $400 \mu \mathrm{m}$ (diameter). A 
hemispherical analyzer was used for data acquisition and the data was analyzed with the Avantage software packages version 5.979 from Thermo Fisher.

\subsection{ICP-OES}

The catalyst samples were decomposed by fusion with potassium pyrosulphate, and dissolved by adding concentrated hydrochloric acid. The element concentration was determined using a Perkin Elmer model Optima 3000 ICP/OES analyser.

\subsection{BET}

The specific surface area (SSA) was measured on the fresh catalyst, after degassing at $350{ }^{\circ} \mathrm{C}$ under vacuum, by nitrogen adsorption at its boiling point using multipoint BET theory with four points in the $\mathrm{p} / \mathrm{p}_{0}=0.15$ to 0.3 range (Quantachrome NOVAtouch LX2). 


\section{Results}

\subsection{Activity measurements}

The activity of the synthesized iron molybdate/molybdenum oxide catalyst (SSA $=4.7 \mathrm{~m}^{2} / \mathrm{g}$ ) was measured over time in the four experiments. Each of the experiments (TOS =10, 100, 250 and $600 \mathrm{~h}$ ) showed the same development in activity over time, showing that the activity measurements are reproducible (Figure S2 $\uparrow$ ). The activation energy $(57 \pm 2 \mathrm{~kJ} / \mathrm{mol})$ and pre-exponential factor of the catalyst was determined prior to each experiment by measuring the reaction rate constant at four temperatures and applying the Arrhenius equation (Figure S3†).

The results of the experiment for $600 \mathrm{~h}$ on stream are shown in Figure 1 . The activity showed an initial decrease from $\sim 100$ to $48 \%$ relative rate (conversion $=47-25 \%$ and catalyst temp. $=398-384{ }^{\circ} \mathrm{C}$, see Figure $\mathrm{S} 4 \dagger$ ), followed by an increase to $\sim 155 \%$ relative rate (conversion $\approx 68 \%$ ), thus exceeding the activity of the fresh catalyst. Moreover, the combined $\mathrm{CH}_{2} \mathrm{O}$ and DME selectivity was above $>96 \%$ at all times. DME will mainly be converted to formaldehyde yielding high overall selectivity at total conversion. Small amounts of CO and $\mathrm{CO}_{2}$ were produced with an overall increasing trend with time on stream to about $3.2 \%$ at $600 \mathrm{~h}$. Due to potential further oxidation of $\mathrm{CH}_{2} \mathrm{O}$, the $\mathrm{CO}$ and $\mathrm{CO}_{2}$ formation would be higher at total conversion with slightly lower overall $\mathrm{CH}_{2} \mathrm{O}$ selectivity. Initially the catalyst temperature followed the development of the activity due the exothermic reactions. However, with increasing $\mathrm{CO}$ and $\mathrm{CO}_{2}$ selectivity at the end of the experiment the catalyst temperature kept increasing, since the combustion reactions are more exothermic than the selective oxidation reaction.

The activity of a comparable commercial catalyst has been measured for $100 \mathrm{~h}$ on stream at similar reaction conditions and a similar trend in the development of the activity and selectivity was observed. 


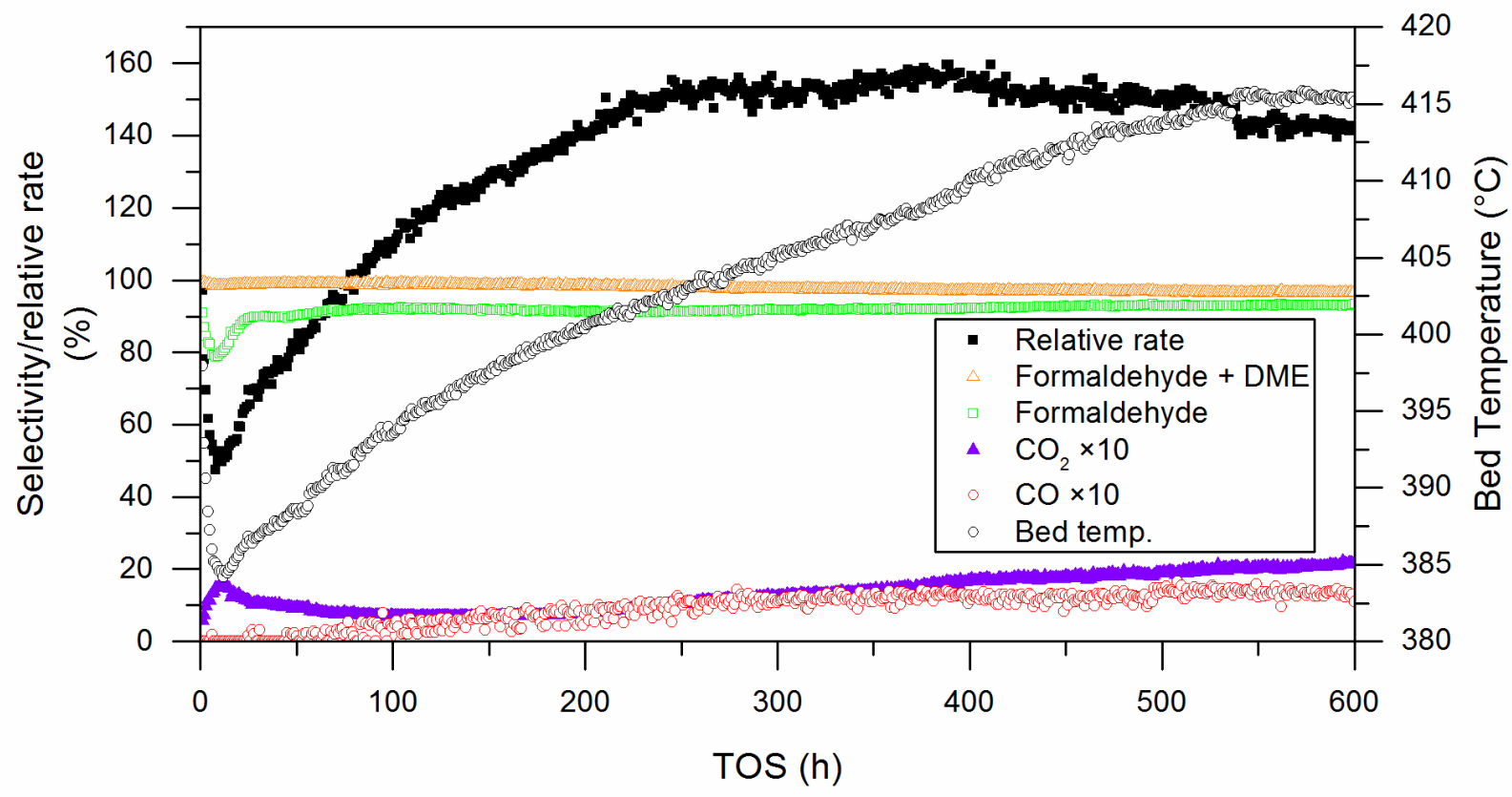

Figure 1 - $\mathrm{MeOH}$ conversion, formaldehyde selectivity, formaldehyde + DME selectivity, $\mathrm{CO}$ selectivity, $\mathrm{CO}_{2}$ selectivity (C-mol \%) and catalyst temperature. Operating conditions: 25 mg catalyst mixed with $170 \mathrm{mg} \mathrm{SiC}$, 157.5 NmL/min gas feed: $10 \%$ O2, 5 \% MeOH in N2. Ambient pressure. Methanol conversion $=\mathbf{2 3 - 7 0} \%$.

\subsection{XRD and Raman spectroscopy}

The X-ray diffraction (XRD) patterns and Raman spectra of the fresh and spent catalyst samples revealed a significant molybdenum loss over time (Figure 2, Figure 3, Figure S5 $\uparrow$ and Figure S6 $†$ ). XRD gives mainly information about the bulk of the samples, while Raman spectroscopy is performed on single positions in the sample (special resolution $\sim 10 \mu \mathrm{m}$ ), yielding information about the local presence of the phases. The $\mathrm{Mo} / \mathrm{Fe}$ ratio were estimated from the Rietveld refined phase composition under the assumptions of only stoichiometric phases and no presence of $\mathrm{X}$-ray amorphous phases. The Mo/Fe ratios and phase compositions are shown in Table 2.

The crystal size for all samples were $\sim 200 \mathrm{~nm}$. The fresh catalyst consisted of $\mathrm{Fe}_{2}\left(\mathrm{MoO}_{4}\right)_{3}$ and $\alpha-\mathrm{MoO}_{3}$ which is indicated by the reflections at $2 \theta=12.75,23.35$ and $27.34^{\circ}$ respectively in the XRD patterns and bands belonging to $\alpha-\mathrm{MoO}_{3}\left(818,993,665,128,116 \mathrm{~cm}^{-1}\right)$ and $\mathrm{Fe}_{2}\left(\mathrm{MoO}_{4}\right)_{3}\left(782,990,966 \mathrm{~cm}^{-1}\right)$ in the Raman spectra. The corresponding Mo/Fe ratio (XRD) of the fresh catalyst is lower than the ICP-OES measured ratio. This is most likely due to some amorphous $\mathrm{MoO}_{\mathrm{x}}$ present on the catalyst surface, as determined by STEM line scans (see Section 3.3), which is not detected by XRD. The XRD pattern and Raman spectra of the fresh catalyst is in 
accordance with catalysts reported in the literature [28], [29]. After $10 \mathrm{~h}$ on stream no $\mathrm{MoO}_{3}$ was detected in the sample, which is due to the volatilization of $\mathrm{MoO}_{3}$ under reaction conditions. In the Raman spectra some bands belonging to the less molybdenum rich $\beta-\mathrm{FeMoO}_{4}\left(925,875 \mathrm{~cm}^{-1}\right)$ started to be visible, along with $\mathrm{Fe}_{2}\left(\mathrm{MoO}_{4}\right)_{3}$, indicating slight reduction and Mo loss from the iron molybdate phase. $\mathrm{MoO}_{3}$ has a replenishing effect on the iron molybdate phase [30], [31], which is most likely the reason for the low degree of reduction in the initial $10 \mathrm{~h}$ on stream. After $100 \mathrm{~h}$ on stream reduction of $\mathrm{Fe}_{2}\left(\mathrm{MoO}_{4}\right)_{3}$ to $\beta-\mathrm{FeMoO}_{4}$ was also detected by XRD, where $\beta-\mathrm{FeMoO}_{4}$ is indicated by the reflection at $2 \theta=26.17^{\circ}$. In the Raman spectra the intensity of the bands belonging to $\beta-\mathrm{FeMoO}_{4}$ increased, while the intensity of the $\mathrm{Fe}_{2}\left(\mathrm{MoO}_{4}\right)_{3}$ bands reduced. Similar observations of $\beta$-FeMoO 4 formation under redox conditions have been observed by O'Brien et al. [32].

After $250 \mathrm{~h}$ on stream the intensity of the reflections and bands belonging to $\beta-\mathrm{FeMoO}$ were increased and decreased for $\mathrm{Fe}_{2}\left(\mathrm{MoO}_{4}\right)_{3}$. Furthermore, Raman bands at 162, 707 and $846 \mathrm{~cm}^{-1}$ became visible, indicating the formation of new phases. After $600 \mathrm{~h}$ the catalyst was subject to significant molybdenum loss. Most of the initial $\mathrm{Fe}_{2}\left(\mathrm{MoO}_{4}\right)_{3}$ was reduced to $\beta-\mathrm{FeMoO}_{4}$ and a significant amount of hematite $\left(\mathrm{Fe}_{2} \mathrm{O}_{3}\right)$ was present in the catalyst, which is indicated by XRD reflections at $2 \theta=24.18^{\circ}$ and $2 \theta=33.17^{\circ}$. Furthermore, a new phase of $\beta-\mathrm{MoO}_{3}$ was present indicated by reflections at $2 \theta=23.02^{\circ}$ and $2 \theta=25.04^{\circ}$. Due to the inhomogeneous nature of the sample, Raman gave different spectra at different positions. Representative Raman spectra at two different positions are shown in Figure 3. At the first position (a) the new phases such as $\beta-\mathrm{FeMoO}_{4}$ were dominant, and only trace amounts of $\mathrm{Fe}_{2}\left(\mathrm{MoO}_{4}\right)_{3}$ was detected. Bands at 846, 353, 774 and $900 \mathrm{~cm}^{-1}$ were assigned to the metastable $\beta$ $\mathrm{MoO}_{3}$. However, bands at 682,707 and $812 \mathrm{~cm}^{-1}$ could not be assigned. By increasing the laser power, the nonassigned bands were selectively removed (indicating a high reactivity of this phase), and by increasing the laser power further, the $\beta-\mathrm{MoO}_{3}$ was transformed into the thermodynamically stable $\alpha-\mathrm{MoO}_{3}$ (Figure S7†). The formation of $\beta-\mathrm{MoO}_{3}$ must originate from segregation of Mo from one or both of the iron molybdate phases. At the second position (b) bands belonging to $\mathrm{Fe}_{2} \mathrm{O}_{3}\left(219,284,396\right.$ and $\left.1305 \mathrm{~cm}^{-1}\right)$ were detected. 


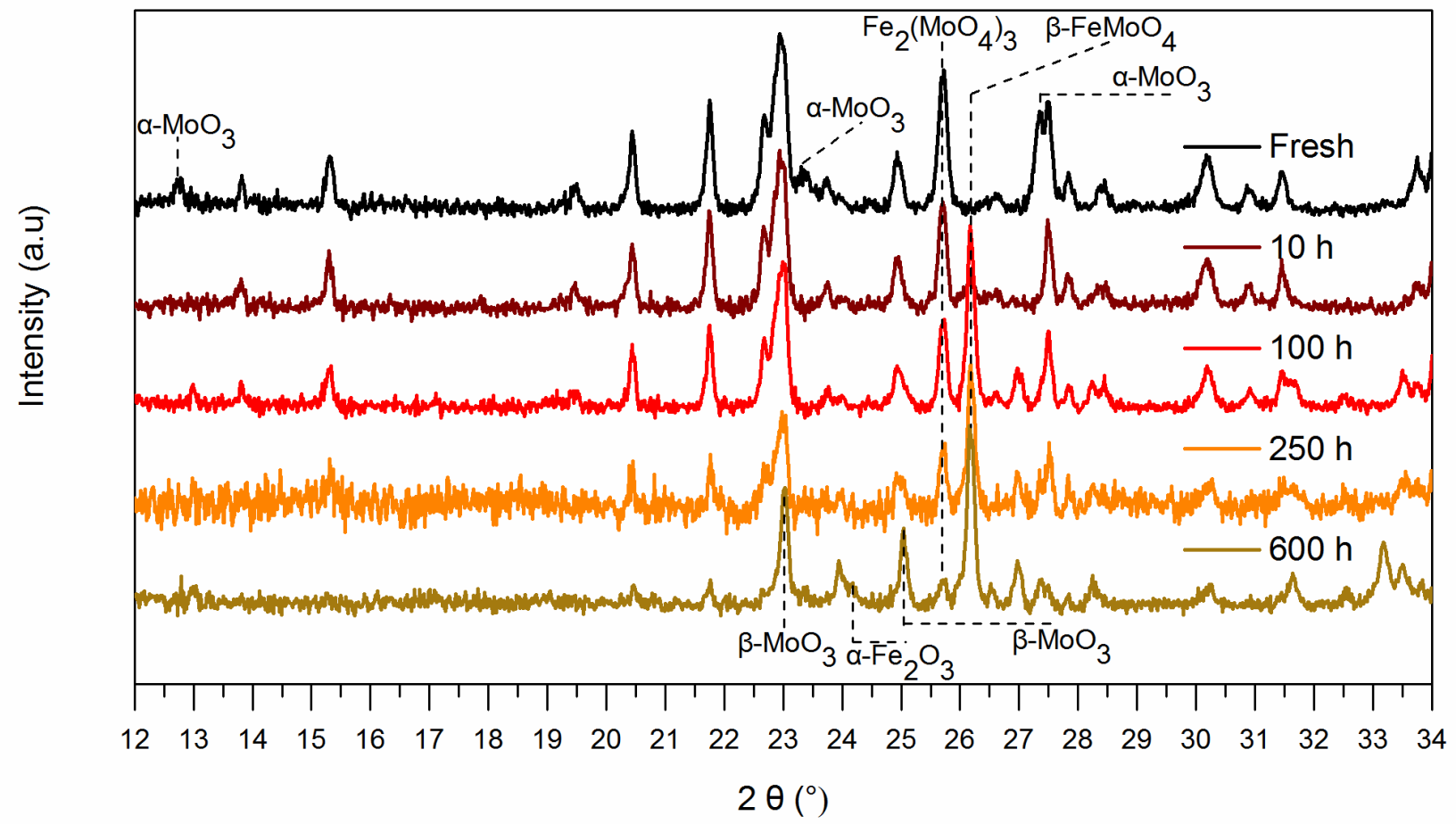

Figure 2 - XRD patterns of the fresh and spent Fe-Mo catalyst samples (TOS = 10, 100, 250 and $600 \mathrm{~h}$ ).

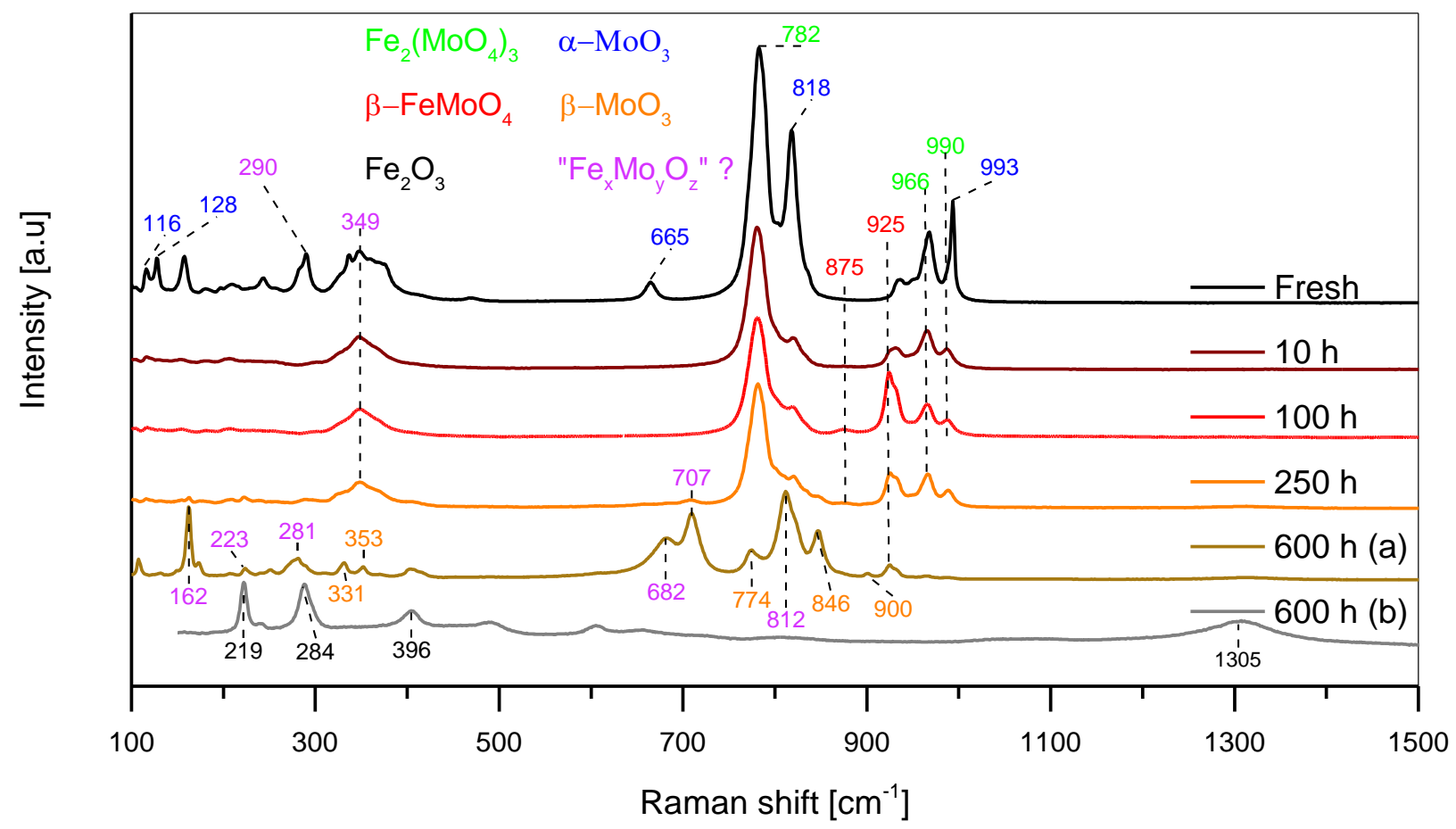

Figure 3 - Raman spectra of the fresh and spent Fe-Mo catalyst samples (TOS = 10, 100, 250 and $600 \mathrm{~h}$ ). Due to the inhomogeneous nature of the catalyst after $600 \mathrm{~h}$ spectra from two representative spots are shown. 
Table 1 - Characterization of the fresh and spent catalysts samples (TOS = 10, 100, 250 and $600 \mathrm{~h}$ ) with, XRD, Raman spectroscopy, ICP-OES and XPS.

\begin{tabular}{|c|c|c|c|c|}
\hline Sample & $\begin{array}{l}\text { Phases According to } \\
\text { Raman } \\
{ }^{*} \text { Small amounts }\end{array}$ & $\begin{array}{c}\text { Phases According to XRD } \\
\text { Phase (wt. \%) }\end{array}$ & $\begin{array}{l}\text { Mo/Fe Bulk Ratio } \\
\text { according to: } \\
{ }^{\text {a }} \text { XRD, }{ }^{\text {b }} \text { ICP-OES }\end{array}$ & $\begin{array}{c}\text { Mo/Fe Surface Ratio } \\
\text { according to: } \\
\text { XPS }\end{array}$ \\
\hline FeMo_Fresh & $\alpha-\mathrm{MoO}_{3}, \mathrm{Fe}_{2}\left(\mathrm{MoO}_{4}\right)_{3}$ & $\mathrm{MoO}_{3}(17), \mathrm{Fe}_{2}\left(\mathrm{MoO}_{4}\right)_{3}(83)$ & $1.90^{\mathrm{a}}, 2.01^{\mathrm{b}}$ & 5.84 \\
\hline FeMo_10h & $\begin{array}{c}\mathrm{Fe}_{2}\left(\mathrm{MoO}_{4}\right)_{3}, \beta- \\
\mathrm{FeMoO}_{4}{ }^{*}\end{array}$ & $\mathrm{Fe}_{2}\left(\mathrm{MoO}_{4}\right)_{3}(100)$ & $1.50^{\mathrm{a}}$ & 0.81 \\
\hline FeMo_100h & $\mathrm{Fe}_{2}\left(\mathrm{MoO}_{4}\right)_{3}, \beta-\mathrm{FeMoO}_{4}$ & $\mathrm{Fe}_{2}\left(\mathrm{MoO}_{4}\right)_{3}(69), \beta-\mathrm{FeMoO}_{4}(31)$ & $1.31^{\mathrm{a}}$ & 0.75 \\
\hline FeMo_250h & $\begin{array}{c}\beta-\mathrm{MoO}_{3}{ }^{*}, \mathrm{Fe}_{2}\left(\mathrm{MoO}_{4}\right)_{3}, \\
\beta-\mathrm{FeMoO}_{4}\end{array}$ & $\mathrm{Fe}_{2}\left(\mathrm{MoO}_{4}\right)_{3}(64), \beta-\mathrm{FeMoO}_{4}(36)$ & $1.28^{\mathrm{a}}$ & 0.66 \\
\hline FeMo_600h & $\begin{array}{c}\beta-\mathrm{MoO}_{3}, \mathrm{Fe}_{2}\left(\mathrm{MoO}_{4}\right)_{3}{ }^{*}, \\
\beta-\mathrm{FeMoO}_{4}, \mathrm{Fe}_{2} \mathrm{O}_{3}\end{array}$ & $\begin{array}{c}\beta-\mathrm{MoO}_{3}(11), \mathrm{Fe}_{2}\left(\mathrm{MoO}_{4}\right)_{3}(20) \\
\beta-\mathrm{FeMoO}_{4}(33), \mathrm{Fe}_{2} \mathrm{O}_{3}(36)\end{array}$ & $0.49^{\mathrm{a}}$ & 0.44 \\
\hline
\end{tabular}




\subsection{SEM and STEM images}

The scanning electron microscopy (SEM) images (Figure S $8 \uparrow-\mathrm{S} 17 \dagger$ ) and scanning transmission electron microscope (STEM) elemental mapping (Figure S18 $\uparrow-S 27 \dagger$ ), both coupled with energy dispersive X-ray spectroscopy (EDS) showed the changing morphology and elemental composition of the catalyst samples with increasing time on stream. Images of the fresh catalyst (Figure 4) showed the presence of irregularly shaped $\mathrm{MoO}_{3}$ particles around $\sim 1 \mu \mathrm{m}$ in size. Furthermore, the major part of the sample consisted of smaller $\mathrm{Fe}_{2}\left(\mathrm{MoO}_{4}\right)_{3}$ crystals. STEM line scan (Figure 5) revealed a surface enrichment of Mo on the $\mathrm{Fe}_{2}\left(\mathrm{MoO}_{4}\right)_{3}$ crystals of app. $5 \mathrm{~nm}$. On the images of the catalyst after 10 and $100 \mathrm{~h}$ on stream no $\mathrm{MoO}_{3}$ crystals were observed (Figure 6 and Figure 7, Figure S14 $\uparrow-\mathrm{S} 15 \dagger$ and S20 $\uparrow-\mathrm{S} 23 \dagger$ ) and no surface enrichment of Mo was observed. On the images of the samples after 250 and $600 \mathrm{~h}$ on stream almost cubic crystals of $\mathrm{MoO}_{3}$ were observed (Figures S8-S9, S13-S14). The observation of $\mathrm{MoO}_{3}$ crystals after 250 and $600 \mathrm{~h}$ on stream indicates the formation of $\beta$ $\mathrm{MoO}_{3}$ which has monoclinic crystal structure with dimensions very close to cubic [33]. The formation of $\beta$ $\mathrm{MoO}_{3}$ is also shown by XRD and Raman spectroscopy after 250 and $600 \mathrm{~h}$ on stream. A decrease in the Mo content of the iron molybdate crystals was observed as function of time on stream. The surface region was observed to be more iron rich than the crystal bulk for those samples, which indicate that Mo segregates from the crystal bulk to the surface, where it forms volatile species with $\mathrm{MeOH}$ and evaporates. The iron molybdate crystals appear to disintegrate as function of time on stream. This is most likely due to the loss of Mo from the crystal lattice leading to smaller polycrystalline iron molybdate particles. The change in the morphology will most likely lead to increased surface area of the spent catalyst sample. Increased surface area of Mo poor iron molybdate system are likewise observed in the literature for synthesized systems [34]. 


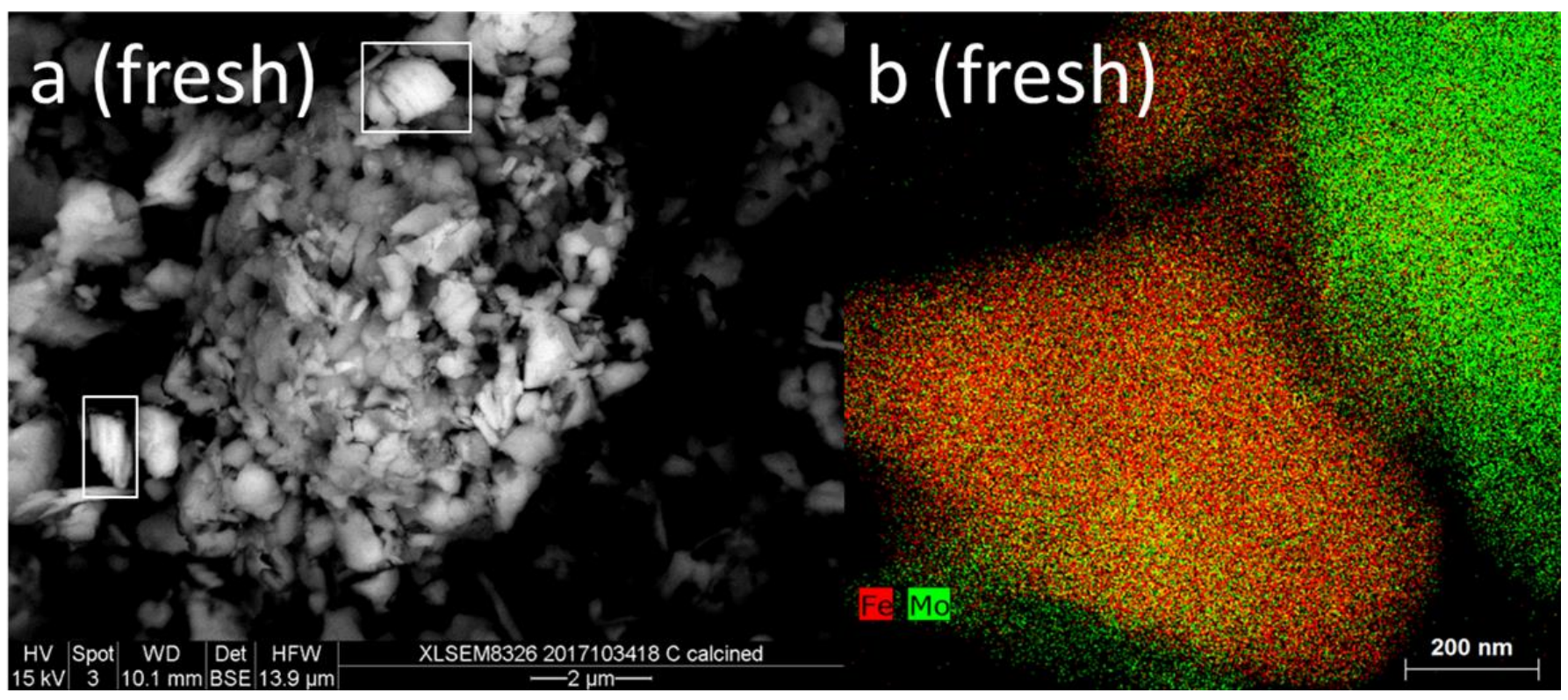

Figure 4 - SEM image of fresh FeMo catalyst (a), white rectangles marks $\mathrm{MoO}_{3}$ crystals. STEM elemental mapping overlap of Fe and Mo (b).

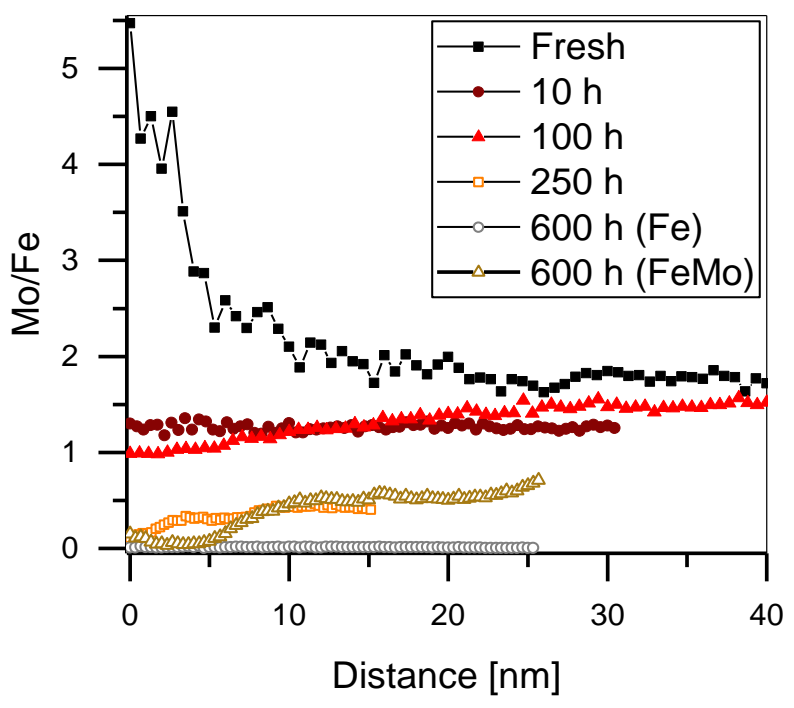

Figure 5 - STEM line scans of fresh and spent FeMo catalyst. $0 \mathrm{~nm}=$ crystal surface. The Mo/Fe atomic ratio is shown. 


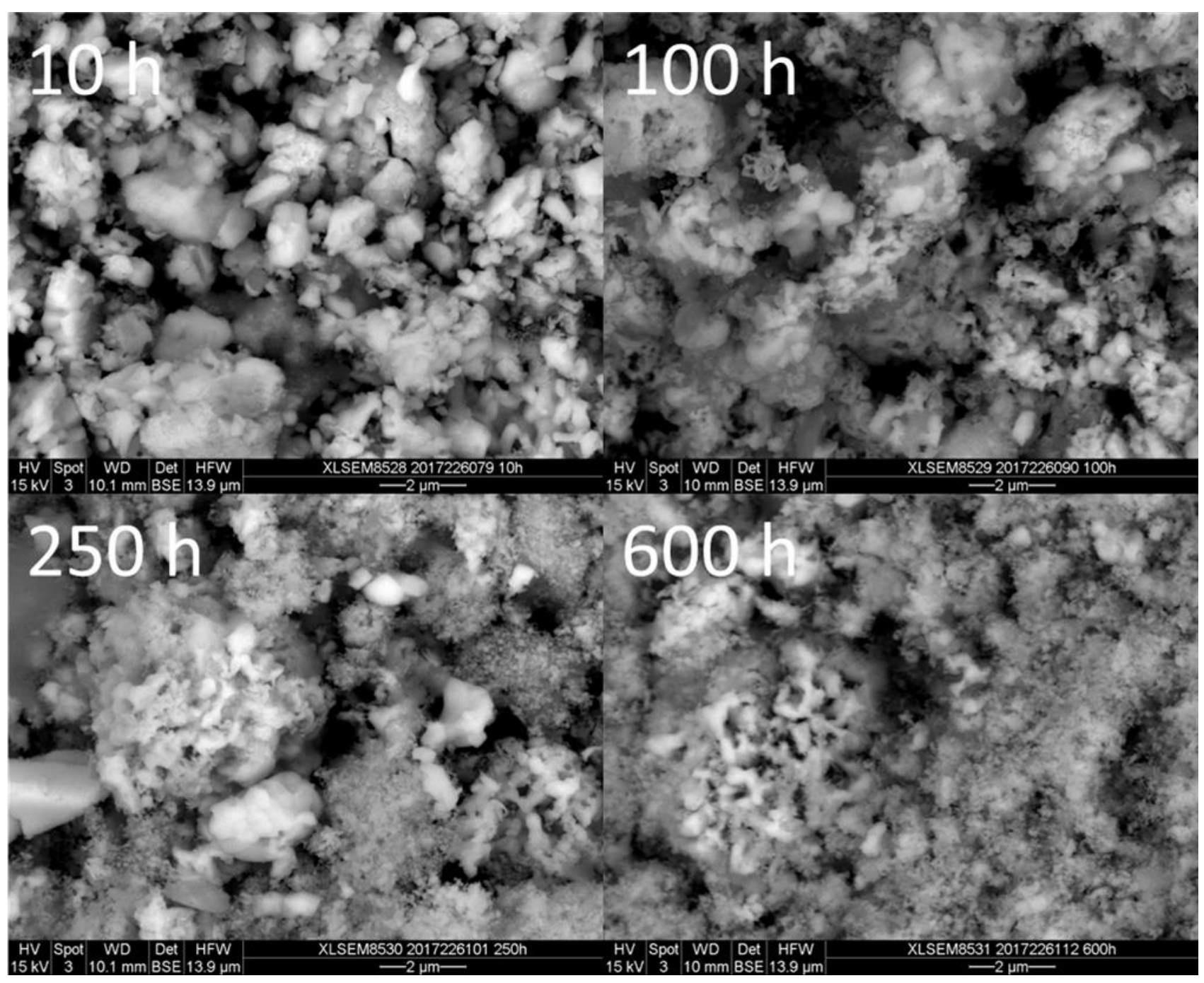

Figure 6 - SEM images of spent FeMo catalyst. TOS $=10$ h, 100 h, $250 \mathrm{~h}$ and $600 \mathrm{~h}$. 


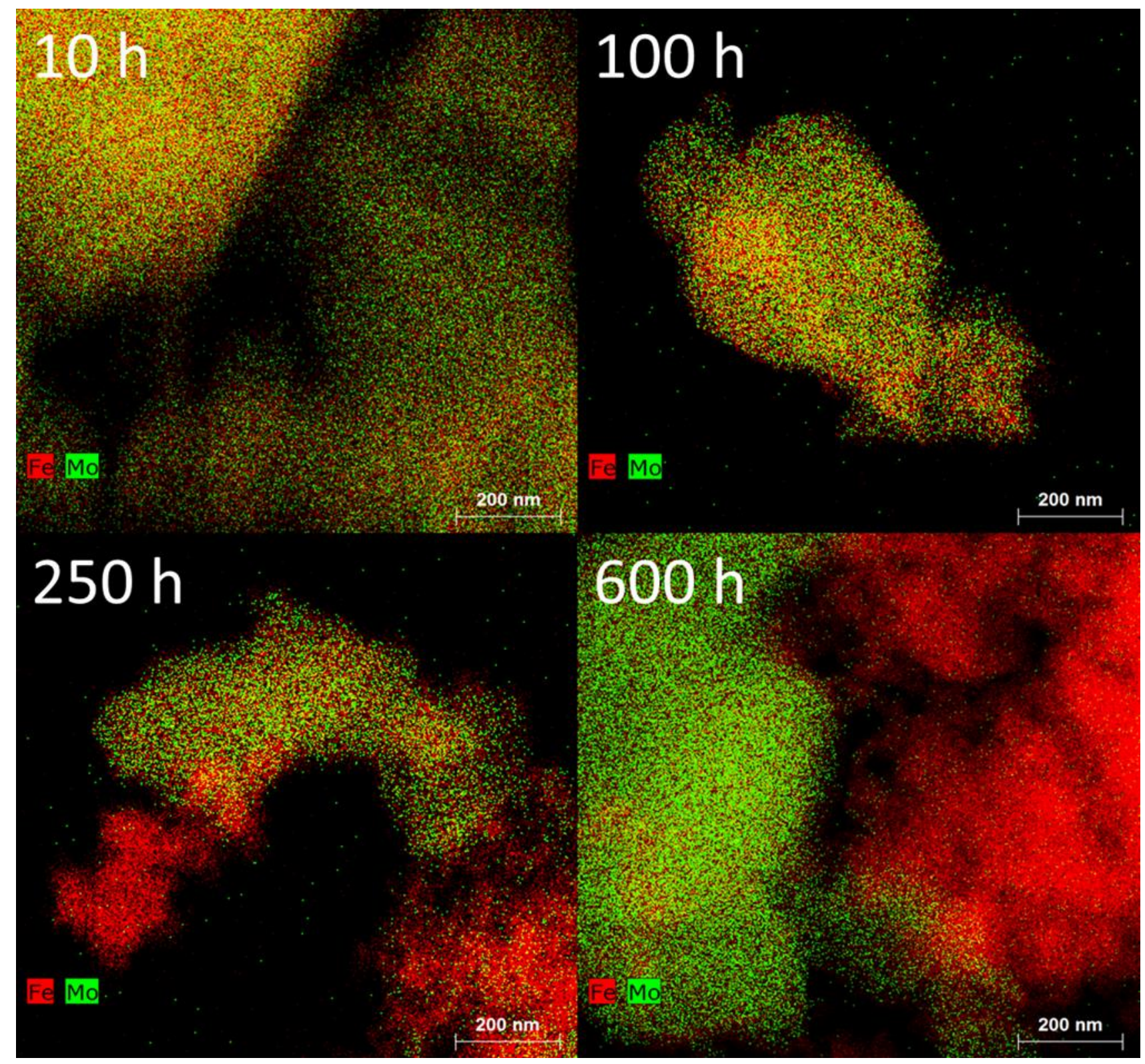

Figure 7 - STEM determination of atomic distributions across FeMo catalyst. TOS = 10 h, 100 h, 250 h and 600 h. 


\subsection{XPS}

X-ray photoelectron spectroscopy (XPS) of the fresh and spent catalysts revealed a significant molybdenum loss from the catalyst surface region over time. The spectra can be seen in Figure S28†. The samples were fitted to a single Mo $3 \mathrm{~d}_{3 / 2}-$ Mo $3 \mathrm{~d}_{5 / 2}$ doublet, which indicate the presence of only one type of molybdenum (VI) oxide species. The Fe $2 \mathrm{p}_{3 / 2}$ peak was successfully fitted with two individual components, which indicate the presence of two iron (II and III) oxide species. However, these species overlap closely, which makes quantification of the separate species highly uncertain. The Fe $2 \mathrm{p}_{3 / 2}$ binding energies are reported as fitted to a single $\mathrm{Fe} 2 \mathrm{p}_{3 / 2}$ peak. The binding energies can be seen in Table 2 and the Mo/Fe ratio can be seen in Table 1. Similar binding energies have been reported in the literature [35], [36].

Table 2 - Peak positions in XPS spectra of fresh and spent catalysts.

\begin{tabular}{lcc}
\hline & \multicolumn{2}{c}{ Binding energy (eV) } \\
\cline { 2 - 3 } Catalysts sample & Mo 3d $\mathbf{5} / \mathbf{2}$ & Fe 2p $\mathbf{3} / 2$ \\
\hline FeMo_Fresh & 234.3 & 713.6 \\
FeMo_10 h & 231.4 & 709.9 \\
FeMo_100 h & 232.1 & 710.7 \\
FeMo_250 h & 231.5 & 710.2 \\
FeMo_600 h & 231.6 & 710.0 \\
\hline
\end{tabular}




\section{Discussion}

The catalytic performance (Figure 1) and compositional changes (Table 1) observed for the synthesized iron molybdate catalyst $(\mathrm{Mo} / \mathrm{Fe}=2)$ reveal significant Mo loss in a period of $600 \mathrm{~h}$ on stream at the reaction conditions ( $5 \% \mathrm{MeOH}, 10 \% \mathrm{O}_{2}$ in $\left.\mathrm{N}_{2}: \mathrm{W} / \mathrm{F}=1.2 \mathrm{~g}_{\mathrm{cat}} / \mathrm{mol}_{\mathrm{MeOH}}\right)$ and elevated temperature (catalyst = $384-$ $416^{\circ} \mathrm{C}$ ). The catalyst was selective mainly towards formaldehyde throughout the experiment even at significant Mo loss and formation of iron rich species.

\subsection{TOS $=0-10 \mathrm{~h}$}

The XRD and Raman spectroscopy show that no $\mathrm{MoO}_{3}$ is present in the catalyst after $10 \mathrm{~h}$ on stream. This is due to the volatilization of $\mathrm{MoO}_{3}$ with $\mathrm{MeOH}$ leading to transport of Mo out of the catalyst bed. This is possible since the experiments are performed with moderate conversion, so the $\mathrm{MeOH}$ concentration is significant throughout the catalyst bed. The initial migration of the excess Mo observed in this work is comparable with the migration occurring in the initial part of the catalytic zone in an industrial reactor, where excess Mo likewise volatilizes and is transported through the reactor. Activity measurements of the spent catalyst from industrial plants and industrial like experiments show a significant drop in activity when the catalyst loses its excess $\mathrm{MoO}_{3}$ [12], [18]. This activity drop is likewise observed in this work after $10 \mathrm{~h}$ on stream. Furthermore, Raman spectroscopy showed low intensity bands belonging to $\beta-\mathrm{FeMoO}_{4}$, STEM line scan after $10 \mathrm{~h}$ on stream showed a Mo/Fe ratio corresponding to a mixture of $\mathrm{FeMoO}_{4}$ and $\mathrm{Fe}_{2}\left(\mathrm{MoO}_{4}\right)_{3}$ and XPS showed a Mo/Fe ratio of 0.81, which all indicate that the iron molybdate crystals are subject to Mo loss at the surface region.

The measured surface Mo/Fe ratio might be misleading, because XPS is not only surface layer sensitive. The signal originates from the top 1-2 nm and for the iron molybdate system approximately $20 \%$ of the total XPS signal has been estimated to originate from the surface layer alone [35]. Thus, the true surface monolayer might have a different Mo/Fe ratio than the one measured with XPS. The rather high selectivity might suggest a Mo rich surface layer [31]. Assuming that $20 \%$ of the XPS signal originates from a Mo surface monolayer (ML) and that the sublayers have an evenly distributed $\mathrm{Mo} / \mathrm{Fe}$ ratio, the sublayer $\mathrm{Mo} / \mathrm{Fe}$ ratio would be $\sim 0.45$, which correspond to a significantly iron enriched composition. However, it has been shown by Brookes et al. [31] that a layer of $\mathrm{MoO}_{\mathrm{x}}$ on top of $\mathrm{Fe}_{2} \mathrm{O}_{3}$ can result in a selective catalyst at moderate conversion levels.

Dias et al. [28] studied the catalytic effect of varying the number of Mo ML on top of iron molybdate. Their data show that at $3 \mathrm{ML}$ the catalyst is relatively active and selective towards $\mathrm{CH}_{2} \mathrm{O}$. However, when the Mo ML is decreased to $0.5 \mathrm{ML}$ the catalyst become less active and more selective towards DME. The observations by Soares et al. support the observations in this work of increasing DME formation during the initial $10 \mathrm{~h}$ on stream 
where all $\mathrm{MoO}_{3}$ and the surface enrichment of $\mathrm{MoO}_{x}$ on $\mathrm{Fe}_{2}\left(\mathrm{MoO}_{4}\right)_{3}$ evaporate from the catalyst, as determined by XRD, Raman spectroscopy, STEM and XPS.

In the present work, the selectivity towards $\mathrm{CO}$ and $\mathrm{CO}_{2}$ was higher compared to the observed selectivity of commercial catalysts [1]. This could be due to the high temperatures $\left(384-416{ }^{\circ} \mathrm{C}\right)$ where the temporary reduction of the catalyst surface during the conversion of methanol to formaldehyde becomes relative faster than the re-oxidization of the catalyst, leading to $\mathrm{CO}$ and $\mathrm{CO}_{2}$ selective sites on the catalyst [37].

\subsection{TOS $=10-250 \mathrm{~h}$}

XRD shows that the iron molybdate phase remaining after $10 \mathrm{~h}$ on stream is subject to further Mo loss leading to reduction and formation of $\beta-\mathrm{FeMoO}_{4}$ with an overall bulk Mo/Fe ratio of 1.28 after TOS $=250 \mathrm{~h}$. STEM line scan showed iron rich surface regions and XPS shows a Mo/Fe ratio of 0.66, which indicate further Mo loss at the surface region. The lower Mo content at the surface region compared to the bulk indicates that Mo from the bulk phase $\left(\mathrm{Fe}_{2}\left(\mathrm{MoO}_{4}\right)_{3}\right)$ segregates to the surface, where it evaporates, leaving $\mathrm{FeMoO}$ and $\mathrm{Fe}_{2} \mathrm{O}_{3}$ as an outer layer of the crystals. The tendency of Mo segregation to the surface is also reported elsewhere in the literature [31], [38].

House et al. [34] studied the effect of varying the $\mathrm{Mo} / \mathrm{Fe}$ ratio in the iron molybdate/molybdenum oxide catalyst system. Figure 8 shows some of the presented data with respect to conversion (Figure 8 (a)) and selectivity (Figure 8 (b)) at $190{ }^{\circ} \mathrm{C}$, both as function of the catalyst Mo content. It can be seen that for the catalyst with very low Mo content $(\mathrm{Mo} / \mathrm{Fe}=0.02)$ the conversion is approximately half compared to the stoichiometric catalyst $(\mathrm{Mo} / \mathrm{Fe}=1.5)$. The conversion over $\mathrm{Fe}_{2} \mathrm{O}_{3}$ was app. $0 \%$ at this temperature. The low activity of pure $\mathrm{Fe}_{2} \mathrm{O}_{3}$ is also reported elsewhere [30]. For the catalysts with low Mo contents $(\mathrm{Mo} / \mathrm{Fe}=0.2$ and 0.5$)$ the conversion is close to twofold higher than the stoichiometric catalyst. It should be mentioned that the change in activity is likely a surface area effect as the iron-rich catalysts have close to one order of magnitude larger surface areas than the stoichiometric catalyst. SEM images in the current work show that iron molybdate crumbles, which most likely will increase the surface area of the catalyst sample. Due to the small sample size it has not been possible to verify this by e.g. $\mathrm{N}_{2}$ adsorption using the Brunauer-Emmett-Teller (BET) theory.

Furthermore, it can be seen that for catalysts with a Mo/Fe ratio $\geq 0.5$ that the combined formaldehyde and DME selectivity is above $90 \%$ at conversion levels between $20-25 \%$. However, at increased conversion (40-50\%) the selectivity significantly decreases as function of decreasing Mo content in the catalysts indicating that the iron-rich catalysts are active in oxidizing formaldehyde to $\mathrm{CO}$ and $\mathrm{CO}_{2}$. When comparing the data presented by House et al. [34] with the current work it should be mentioned that the temperatures are approximately $200{ }^{\circ} \mathrm{C}$ higher in the current work. At elevated temperature the oxidation of methanol and formaldehyde could 
potentially form $\mathrm{CO}$ and $\mathrm{CO}_{2}$. However, this is not the case for the current work, possibly due to low coverage of formaldehyde at the higher temperature, and the two sets of data are reasonably comparable.
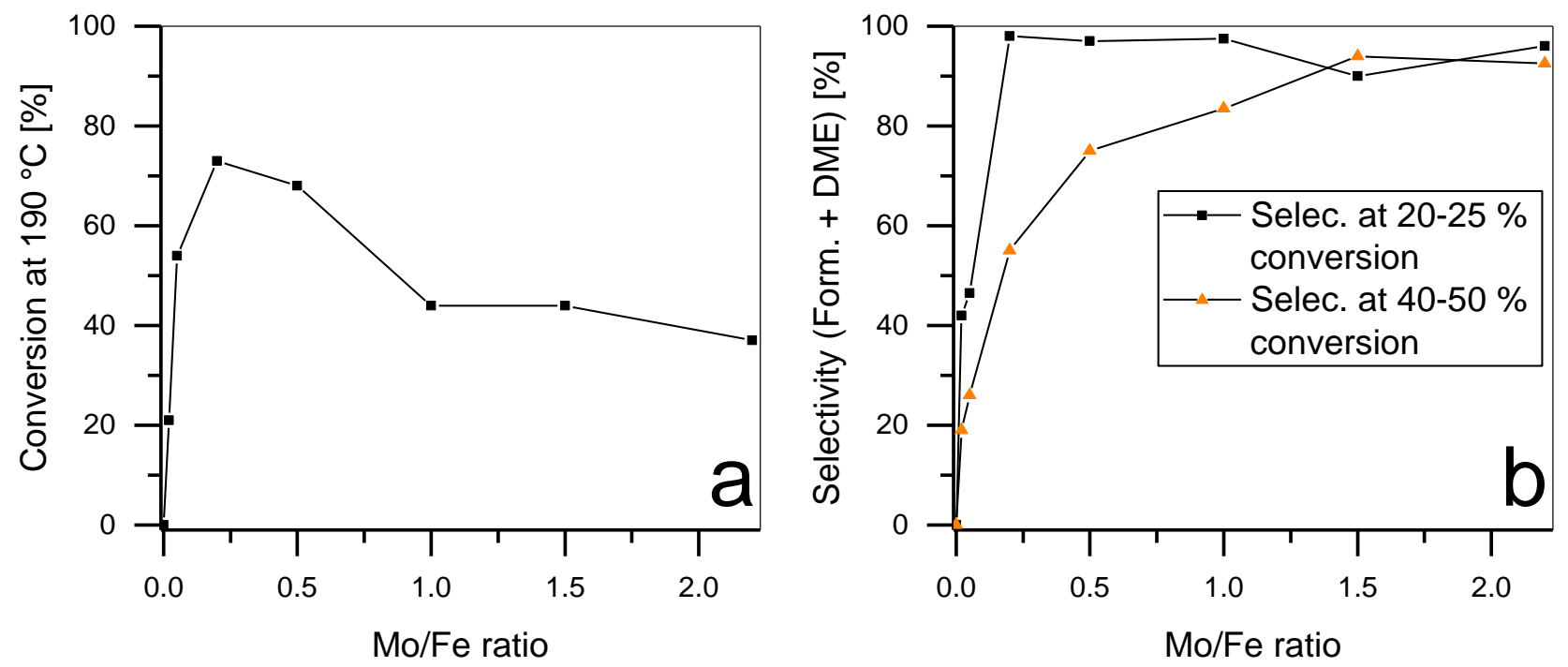

Figure 8 - Left: Conversion of $1 \mu \mathrm{L}$ of methanol pulses as function of Mo content. Catalyst surface area for increasing Mo content: 16.8, 34.0, 65.6, 55.4, 38.7, 7.8 and $6.7 \mathrm{~m}^{2} / \mathrm{g}$. Right: Combined formaldehyde and DME selectivity as function of Mo content (the temperature for selectivity at $20-25 \%$ conversion is $160-200{ }^{\circ} \mathrm{C}$ and for selectivity at $40-50 \%$ conversion is $175-215{ }^{\circ} \mathrm{C}$ ). Data adapted from House et al. [34].

\subsection{TOS $=250-600 \mathrm{~h}$}

For the sample after TOS $=600 \mathrm{~h}$ XRD shows the presence of $\mathrm{Fe}_{2}\left(\mathrm{MoO}_{4}\right)_{3}, \mathrm{FeMoO}_{4}, \mathrm{Fe}_{2} \mathrm{O}_{3}$ and $\beta-\mathrm{MoO}_{3}$ with an overall $\mathrm{Mo} / \mathrm{Fe}$ ratio of 0.49 , which indicates a significant loss of Mo. STEM line scans of the surface regions shows no Mo on the $\mathrm{Fe}_{2} \mathrm{O}_{3}$ crystals and an iron rich surface region for the iron molybdate crystals compared to the bulk. XPS shows a Mo/Fe ratio of 0.44 , which indicates further segregation and volatilization of Mo. After $400 \mathrm{~h}$ on stream the activity of the catalyst starts to decrease slowly, which is probably due to formation of the less active $\mathrm{Fe}_{2} \mathrm{O}_{3}$. Furthermore, the selectivity slowly decreases, due to formation of significant amounts of iron rich surfaces. The newly formed $\mathrm{Fe}_{2} \mathrm{O}_{3}$ is selective towards $\mathrm{CO}_{2}$. However, since $\mathrm{Fe}_{2} \mathrm{O}_{3}$ is also significantly less active the overall selectivity of the catalyst remains high, and the combined formaldehyde and DME selectivity after $600 \mathrm{~h}$ on stream is $97 \%$ with the remainder being $\mathrm{CO}$ and $\mathrm{CO}_{2}$. This shows that even small amounts of molybdenum present at the catalyst surface yield a rather selective catalyst. This has also been reported elsewhere in the literature [31], [35].

To the authors knowledge the formation of $\beta-\mathrm{MoO}_{3}$ in the iron molybdate system under reaction conditions has not been observed elsewhere in the literature. Since no excess $\mathrm{MoO}_{3}$ is observed after $\mathrm{TOS}=10 \mathrm{~h}$, the Mo in the 
formed $\beta-\mathrm{MoO}_{3}$ must originate from the iron molybdate. The formation is only observed after significant Mo depletion of the iron molybdate, which might indicate that the Mo originates from the reduced phase $(\mathrm{FeMoO})$ as follows (9):

$$
\mathrm{FeMoO}_{4}+\frac{1}{4} \mathrm{O}_{2} \rightarrow \frac{1}{2} \mathrm{Fe}_{2} \mathrm{O}_{3}+\beta-\mathrm{MoO}_{3}
$$

Pham et al. [39] synthesized $\beta-\mathrm{MoO}_{3}$ and studied its catalytic performance compared to the thermodynamically stable $\alpha-\mathrm{MoO}_{3}$ under reaction conditions $\left(6.2 \% \mathrm{MeOH}\right.$ in air, $\left.\mathrm{W} / \mathrm{F}=15 \mathrm{~g}_{\mathrm{cat}} \mathrm{h} \mathrm{mol}{ }^{-1} \mathrm{MeOH}\right)$ in an fixed bed reactor. They concluded that the synthesized $\beta-\mathrm{MoO}_{3}$ transforms to $\alpha-\mathrm{MoO}_{3}$ at $350{ }^{\circ} \mathrm{C}$. This is below the catalyst temperature in the present study, which means that the $\beta-\mathrm{MoO}_{3}$ observed in this study should have quickly transformed to $\alpha-\mathrm{MoO}_{3}$. However, in the experiment reported by Pham et al. [39] methanol is fully converted and due to the exothermic reaction the catalyst bed might be subject to a hot spot and the actual temperature where $\beta-\mathrm{MoO}_{3}$ transformed could thus be higher. Furthermore, the prepared $\beta-\mathrm{MoO}_{3}$ was calcined at $350{ }^{\circ} \mathrm{C}$ as part of the synthesis procedure without transforming to the $\alpha-\mathrm{MoO}_{3}$. The transition temperature from $\beta$ to $\alpha$ $\mathrm{MoO}_{3}$ is moreover reported in the literature with high variation from $387^{\circ} \mathrm{C}$ [40] to $450{ }^{\circ} \mathrm{C}$ [41]. The data in the current work show that $\beta-\mathrm{MoO}_{3}$ must be rather stable at the reaction conditions, since it does not evaporate after TOS $=600 \mathrm{~h}$.

In the present work the degradation of catalyst particles in the sieve fractions 150-250 $\mu \mathrm{m}$ were shown to maintain high formaldehyde selectivity (> 97\%) even at significant degradation and loss of Mo. However, this is observed at moderate conversion levels where the oxidation of formaldehyde to $\mathrm{CO} / \mathrm{CO}_{2}$ is limited by the short residence time in the bed. At total conversion of $\mathrm{MeOH}$ the further oxidation of formaldehyde would most likely be more intensive yielding lower selectivity. Brookes et al. [31] did likewise observe decreasing selectivity at increasing $\mathrm{MeOH}$ conversion.

When comparing the present work with the industrial process it must be taken into account that $\mathrm{MeOH}$ is converted to formaldehyde within a much larger catalyst pellet. $\mathrm{MeOH}$ is converted through the pellet and it must be expected that the degradation at the pellet core is less significant. To compare the current work and other studies in the literature on smaller catalyst particles, a degradation study of an entire pellet would be of high interest and is ongoing in our laboratory. 


\section{Conclusion}

In the present study an iron molybdate/molybdenum oxide catalyst $(\mathrm{Mo} / \mathrm{Fe}=2)$ was synthesized using hydrothermal synthesis followed by calcination $\left(535^{\circ} \mathrm{C} / 2 \mathrm{~h}\right)$. During operation $(25 \mathrm{mg}$ catalyst, feed flow $=$ $\sim 157.5 \mathrm{NmL} / \mathrm{min}, \sim 5 \% \mathrm{MeOH}, 10 \% \mathrm{O}_{2}$ in $\mathrm{N}_{2}$, temp. $=384-416^{\circ} \mathrm{C}$ ) the activity and compositional changes in the catalyst have been investigated by comprehensive characterization. All of the excess $\alpha-\mathrm{MoO}_{3}$ volatilized during the initial $10 \mathrm{~h}$ under reaction conditions and the surface of the iron molybdate crystals were subject to loss of Mo leading to iron rich surface species. The loss of $\mathrm{MoO}_{3}$ in the initial $10 \mathrm{~h}$ resulted in a $50 \%$ decrease in activity of the catalyst. The initial decrease in activity may be due to the decreasing amount of $\mathrm{MoO}_{x}$ on the catalyst surface as reported by Dias et al. [28]. While excess molybdenum oxide is present in the catalyst, it has a replenishing effect on the iron molybdate phase.

In the period following the initial volatilization of $\alpha-\mathrm{MoO}_{3}$, the iron molybdate phase is subject to leaching of Mo leading to iron rich phases $\left(\mathrm{FeMoO}_{4}\right.$ and $\left.\mathrm{Fe}_{2} \mathrm{O}_{3}\right)$. The selectivity only decreases slightly throughout the experiment $(\mathrm{TOS}=600 \mathrm{~h}$ ) even at significant loss of molybdenum. This is due to low catalytic activity of the less selective iron rich sites and probably some Mo enrichment of the catalyst surface. After $600 \mathrm{~h}$ the formation of $\beta-\mathrm{MoO}_{3}$ was surprisingly observed, likely originating from the $\beta-\mathrm{FeMoO}$ phase. The $\beta-\mathrm{MoO}_{3}$ appears thermally stable and significantly less volatile compared to the thermodynamically stable $\alpha-\mathrm{MoO}_{3}$, since $\beta-\mathrm{MoO}_{3}$ still remains in the catalyst at the end of the $600 \mathrm{~h}$ experiment.

This work is the first time the structural changes and catalytic performance of the iron molybdate catalyst has been studied at reaction conditions over a period long enough to achieve significant degradation, yielding insights to the structural changes and the corresponding catalytic performance.

\section{Conflict of interest}

There are no conflicts to declare.

\section{Acknowledgments}

This work is a collaboration between the CHEC research center at The Department of Chemical and Biochemical Engineering at Technical University of Denmark (DTU) and Haldor Topsøe A/S. We thank the Independent Research Fund Denmark for the financial support (DFF - 4184-00336). We gratefully acknowledge 
Prof. Jan-Dierk Grunwaldt at Karlsruhe Institute of Technology (KIT) and Assoc. Prof. Christian D. Damsgaard at Technical University of Denmark (DTU) for fruitful discussions during the work.

\section{Supplementary data}

STEM and SEM images, STEM linescans, XPS spectra, activity measurements and Arrhenius plots.

\section{References}

[1] R. Günther, W. Disteldorf, A. O. Gamer, and A. Hilt, “Ullmann's encyclopedia of industrial chemistry,” Weinheim, 2012.

[2] Merchant Research \& Consulting ltd, "World Formaldehyde Production to Exceed 52 Mln Tonnes in 2017," 2016. [Online]. Available: https://mcgroup.co.uk/news/20140627/formaldehyde-production-exceed-52-mln-tonnes.html.

[3] S. K. Bhattacharyya and K. Janakiram, "Kinetics of the Vapor-Phase Oxidation of Methyl on Vanadium Pentoxide Catalyst," Distribution, vol. 136, pp. 128-136, 1967.

[4] E. Soderhjelm, M. P. House, N. Cruise, J. Holmberg, M. Bowker, J.-O. Bovin, and A. Andersson, "On the Synergy Effect in MoO3-Fe-2(MoO4)(3) Catalysts for Methanol Oxidation to Formaldehyde,” Top. Catal., vol. 50, no. 1-4, pp. 145-155, 2008.

[5] G. Fagherazzi and N. Pernicone, "Structural Study of a Methanol Oxidation Catalyst," J. Catal., vol. 16, no. 3, pp. 321-325, 1970.

[6] M. Rellán-Piñeiro and N. López, "The Active Molybdenum Oxide Phase in the Methanol Oxidation to Formaldehyde (Formox Process): A DFT Study,” ChemSusChem, vol. 8, no. 13, pp. 2231-2239, 2015.

[7] M. Carbucicchio and F. Trifiró, "Surface and Bulk Redox Processes in Iron-Molybdate-Based," J. Catal., vol. 85, pp. 77-85, 1976.

[8] G. Alessandrini, L. Cairati, P. Forzatti, P. L. Villa, and F. Trifiro, "Chemical, Structural and Catalytic Modifications of Pure and Doped Iron(III) Molybdate,” J. Less Common Met., vol. 54, no. 2, pp. 373-386, 1977.

[9] A. P. V. Soares, M. F. Portela, A. Kiennemann, and L. Hilaire, "Mechanism of deactivation of iron-molybdate catalysts prepared by coprecipitation and sol - gel techniques in methanol to formaldehyde oxidation," Chem. Eng. Sci., vol. 58, no. 7, pp. 1315-1322, 2003.

[10] M. Bowker, R. Holroyd, A. Elliott, P. Morrall, A. Alouche, C. Entwistle, and A. Toerncrona, "The selective oxidation of methanol to formaldehyde on iron molybdate catalysts and on component oxides," Catal. Letters, vol. 83, no. 3-4, pp. 165-176, 2002.

[11] B. I. Popov, V. N. Bibin, and G. K. Boreskov, "Study of an iron-molybfate oxide catalyst for oxidation of methanol to formaldehyde," Kinet. Catal., vol. 17, no. 2, pp. 322-327, 1976. 
[12] A. Andersson, M. Hernelind, and O. Augustsson, "A study of the ageing and deactivation phenomena occurring during operation of an iron molybdate catalyst in formaldehyde production," Catal. Today, vol. 112, pp. 40-44, 2006.

[13] Q. Xu, G. Jia, J. Zhang, Z. Feng, and C. Li, "Surface phase composition of iron molybdate catalysts studied by UV Raman spectroscopy," J. Phys. Chem. C, vol. 112, no. 25, pp. 9387-9393, 2008.

[14] N. Burriesci, F. Garbassi, M. Petrera, G. Petrini, and N. Pernicone, "Solid State Reactions in Fe-Mo Oxide Catalysts for Methanol Oxidation During Aging in Industrial Plants.," Stud. Surf. Sci. Catal., vol. 6, pp. 115-126, 1980.

[15] B. R. Yeo, G. J. F. Pudge, K. G. Bugler, A. V. Rushby, S. Kondrat, J. Bartley, S. Golunski, S. H. Taylor, E. Gibson, P. P. Wells, C. Brookes, M. Bowker, and G. J. Hutchings, "The surface of iron molybdate catalysts used for the selective oxidation of methanol," Surf. Sci., vol. 648, pp. 163-169, 2016.

[16] A. P. V. Soares, M. F. Portela, and A. Kiennemann, "Methanol Selective Oxidation to Formaldehyde over IronMolybdate Catalysts," Catal. Rev., vol. 47, no. 1, pp. 125-174, 2005.

[17] J. L. Figueiredo, Progress in catalyst deactivation. 1981.

[18] K. I. Ivanov and D. Y. Dimitrov, "Deactivation of an industrial iron-molybdate catalyst for methanol oxidation," Catal. Today, vol. 154, no. 3-4, pp. 250-255, 2010.

[19] A. P. V. Soares, M. F. Portela, A. Kiennemann, and J. M. M. Millet, "Iron-molybdate deactivation during methanol to formaldehyde oxidation: Effect of water," React. Kinet. Catal. Lett., vol. 75, no. 1, pp. 13-20, 2002.

[20] A. M. Beale, S. D. M. Jacques, E. Sacaliuc-Parvalescu, M. G. O’Brien, P. Barnes, and B. M. Weckhuysen, “An iron molybdate catalyst for methanol to formaldehyde conversion prepared by a hydrothermal method and its characterization," Appl. Catal. A Gen., vol. 363, no. 1-2, pp. 143-152, 2009.

[21] M. Høj, T. Kessler, P. Beato, A. D. Jensen, and J. D. Grunwaldt, "Structure, activity and kinetics of supported molybdenum oxide and mixed molybdenum-vanadium oxide catalysts prepared by flame spray pyrolysis for propane OHD," Appl. Catal. A Gen., vol. 472, pp. 29-38, 2014.

[22] M. E. Van Leeuwen, "Derivation of Stockmayer potential parameters," Fluid Phase Equilib., vol. 99, no. 99, pp. 118, 1994.

[23] L. S. Tee, S. Gotoh, and W. E. Stewart, "Molecular parameters for normal fluids," Industial Eng. Chemisrty -Fundam., vol. 5, no. 3, pp. 356-363, 1966.

[24] F. M. Mourits and F. H. A. Rummens, "Critical evaluation of Lennard-Jones and Stockmayer potential parameters and of some correlation methods," Can. J. Chem. Can. Chim., vol. 55, no. 16, pp. 3007-3020, 1977.

[25] S. a R. K. Deshmukh, M. Van Sint Annaland, and J. a M. Kuipers, "Kinetics of the partial oxidation of methanol over a Fe-Mo catalyst," Appl. Catal. A Gen., vol. 289, no. 2, pp. 240-255, 2005.

[26] V. N. Bibin and B. I. Popov, "Kinetics of Methanol Oxidation by Air on Iron-Molybdenum Oxide Catalysts," Kinet. Catal. (Engl. Transl.), vol. 10, no. 6, pp. 1091-1098, 1969.

[27] A. A. Coelho, "TOPAS and TOPAS-Academic: an optimization program integrating computer algebra and crystallographic objects written in C++," J. Appl. Cryst., vol. 51, no. 1, pp. 210-218, 2018.

[28] A. P. S. Dias, F. Montemor, M. F. Portela, and A. Kiennemann, "The role of the suprastoichiometric molybdenum 
during methanol to formaldehyde oxidation over Mo-Fe mixed oxides," J. Mol. Catal. A Chem., vol. 397, pp. 9398, 2015.

[29] M. Bowker, C. Brookes, a. F. Carley, M. P. House, M. Kosif, G. Sankar, I. Wawata, P. P. Wells, and P. Yaseneva, "Evolution of active catalysts for the selective oxidative dehydrogenation of methanol on $\mathrm{Fe} 2 \mathrm{O} 3$ surface doped with Mo oxide," Phys. Chem. Chem. Phys., vol. 15, no. 29, p. 12056, 2013.

[30] Y. Huang, L. Cong, J. Yu, P. Eloy, and P. Ruiz, "The surface evolution of a catalyst jointly influenced by thermal spreading and solid-state reaction: A case study with an $\mathrm{Fe} 2 \mathrm{O} 3-\mathrm{MoO} 3$ system," J. Mol. Catal. A Chem., vol. 302, no. 1-2, pp. 48-53, 2009.

[31] C. Brookes, P. P. Wells, G. Cibin, N. Dimitratos, W. Jones, D. J. Morgan, and M. Bowker, "Molybdenum Oxide on Fe 2 O 3 Core-Shell Catalysts: Probing the Nature of the Structural Motifs Responsible for Methanol Oxidation Catalysis," ACS Catal., vol. 4, pp. 243-250, 2014.

[32] M. G. O’Brien, A. M. Beale, S. D. M. Jacques, and B. M. Weckhuysen, “A Combined Multi-Technique In Situ Approach Used to Probe the Stability of Iron Molybdate Catalysts During Redox Cycling,” Top. Catal., vol. 52, no. 10, pp. 1400-1409, 2009.

[33] J. B. Parise, E. M. McCarron, A. W. Sleight, and E. Prince, "Refinement of the Structure of Beta'MoO\&lt;sub\&gt;3\&lt;/sub\&gt;," Mater. Sci. Forum, vol. 27-28, pp. 85-88, 1988.

[34] M. P. House, A. F. Carley, R. Echeverria-Valda, and M. Bowker, "Effect of varying the cation ratio within iron molybdate catalysts for the selectivev oxidation of methanol," J. Phys. Chem. C, vol. 112, no. 11, pp. 4333-4341, 2008.

[35] M. Bowker, R. Holroyd, M. House, R. Bracey, C. Bamroongwongdee, M. Shannon, and A. Carley, "The selective oxidation of methanol on iron molybdate catalysts," Top. Catal., vol. 48, no. 1-4, pp. 158-165, 2008.

[36] R. Peláez, P. Marín, and S. Ordó, "Applied Catalysis A : General Synthesis of formaldehyde from dimethyl ether on alumina-supported molybdenum oxide catalyst," Appl. Catal. A Gen., vol. 527, pp. 137-145, 2016.

[37] F. Trifiro', V. De Vecchi, and I. Pasquon, "Nature of the Active Component in a Fe2O3-MoO3 Catalyst I. Study on the Catalyst Reduction and Oxidation*," J. Catal., vol. 15, pp. 8-16, 1969.

[38] M. P. House, M. D. Shannon, and M. Bowker, "Surface segregation in iron molybdate catalysts," Catal. Letters, vol. 122, no. 3-4, pp. 210-213, 2008.

[39] T. T. P. Pham, P. H. D. Nguyen, T. T. Vo, H. H. P. Nguyen, and C. L. Luu, "Facile method for synthesis of nanosized $\beta-\mathrm{MoO} 3$ and their catalytic behavior for selective oxidation of methanol to formaldehyde," Adv. Nat. Sci. Nanotechnol., vol. 6, no. 4, p. 45010, 2015.

[40] T. Mizushima, K. Fukushima, H. Ohkita, and N. Kakuta, "Synthesis of $\beta-\mathrm{MoO} 3$ through evaporation of HNO3added molybdic acid solution and its catalytic performance in partial oxidation of methanol," Appl. Catal. A Gen., vol. 326, no. 1, pp. 106-112, 2007.

[41] E. M. I. McCarron, “ß-Mo03: a Metastable Analogue of W03,” J. Chem. Soc., Chem. Commun., vol. 101, pp. 336338, 1986.

[42] J. S. Chung, R. Miranda, and C. O. Bennett, "Mechanism of Partial Oxidation of Methanol over MoO3," J. Catal., 
vol. 114, pp. 398-410, 1988. 